\title{
Is real world evidence influencing practice? A systematic review of CPRD research in NICE guidances
}

\author{
Jessie O. Oyinlola*, Jennifer Campbell and Antonis A. Kousoulis
}

\begin{abstract}
Background: There is currently limited evidence regarding the extent Real World Evidence (RWE) has directly impacted the health and social care systems. The aim of this review is to identify national guidelines or guidances published in England from 2000 onwards which have referenced studies using the governmental primary care data provider the Clinical Practice Research Datalink (CPRD).

Methods: The methodology recommended by Preferred Reporting Items for Systematic Reviews and Meta-Analyses (PRISMA) was followed. Four databases were searched and documents of interest were identified through a search algorithm containing keywords relevant to CPRD. A search diary was maintained with the inclusion/exclusion decisions which were performed by two independent reviewers.

Results: Twenty-five guidance documents were included in the final review (following screening and assessment for eligibility), referencing 43 different CPRD/GPRD studies, all published since 2007. The documents covered 12 disease areas, with the majority $(N=7)$ relevant to diseases of the Central Nervous system (CNS). The 43 studies provided evidence of disease epidemiology, incidence/prevalence, pharmacoepidemiology, pharmacovigilance and health utilisation.

Conclusions: A slow uptake of RWE in clinical and therapeutic guidelines (as provided by UK governmental structures) was noticed. However, there seems to be an increasing trend in the use of healthcare system data to inform clinical practice, especially as the real world validity of clinical trials is being questioned. In order to accommodate this increasing demand and meet the paradigm shift expected, organisations need to work together to enable or improve data access, undertake translational and relevant research and establish sources of reliable evidence.
\end{abstract}

Keywords: Guidance, Real world evidence, Clinical practice research datalink

\section{Background}

It is generally agreed that the provision of healthcare should be based on evidence, principally so that a patient receives the best advice or treatment for their condition [1]. As medical evidence is vast and at times contradictory, it is important to have a standard format which presents the evidence for a specific disease or treatment in a way that will help healthcare professionals to grasp and apply such evidence in everyday practice [2]. Standardised evidence also helps to address issues such as inappropriate

\footnotetext{
* Correspondence: Jessie.Oyinlola@mhra.gsi.gov.uk

Clinical Practice Research Datalink (CPRD), Medicines and Healthcare products Regulatory Agency, 151 Buckingham Palace Road, Victoria London SW1W 9SZ, UK
}

variability among healthcare professionals in the provision of care [3]. Examples of this are guidelines and guidances.

Guidelines and guidances are documents which incorporate current evidence from reviewed sources in order to develop clear and comprehensive recommendations on the prevention, treatment and care of patients with specific diseases and conditions [4]. These documents can then be used by health and social care professionals to practice and the ability to tailor treatment to different clinical situations [5]. Within the UK, the main body responsible for the generation and publication of guidelines 
and guidances is the National Institute for Health and Care Excellence (NICE) whose primary objective is to advise professionals working in the National Health Service (NHS) on how to provide the highest achievable standard of care [6].

Although the process for developing these documents has moved from being primarily expert knowledge based to being primarily evidence based, there is still concern regarding the sources of evidence. There is heavy reliance on Randomised Controlled Trials (RCTs) for generating evidence for clinical guidelines as (according to many 'hierarchies' of evidence) they are thought of as the 'gold standard' [7]. However, there are several disadvantages which make evidence from RCTs appear less practical in terms of application to patient care, a key one being the fact that RCTs are generally conducted under controlled conditions on a small number of patients over a fairly short period of time. Even if treatment proves effective in the trial, this does not mean the same effect will translate into the general population as patients in the 'real world' can often be more diverse in terms of age, ethnicity, gender and tend to have more comorbidities which may have an impact on the efficacy of a treatment [8]. Therefore there is a limit to the type of evidence that can be generated from RCTs to address key clinical questions which clinicians face on a daily basis [9]. Additionally, there is also the cost of running clinical trials [10] and the increased interest in obtaining return on investment in healthcare [1]. One possible solution is the use of routinely collected data or clinical databases, research outputs of which are often collectively called Real World Evidence (RWE).

Since the transition of paper healthcare records to Electronic Health records (EHRs) it has been possible to create large datasets containing important information such as clinical events, laboratory results, treatment history, etc. [11] These are often referred to as big data or Real World Data (RWD) and present several advantages to health care:

- they help to strengthen current understanding of healthcare delivery and the outcomes of patients [12],

- they greatly increase the potential of generating new knowledge as researchers can work to answer important clinical questions (which may otherwise not have been possible) [12] and

- they can support the development of evidencebased personalised medicine through the linking of EHRs to genomic datasets [13]. EHRs may also enable patients to take a more active role in their healthcare by presenting their health records to other healthcare professionals, if and when necessary [14].

Lastly (and in this case more importantly), RWD could help with the dissemination of key information by bridging the knowledge gap for clinicians and by improving the quantity and quality of evidence used in guidelines and guidances. Best evidence can only be generated when starting with the best data [4]. An example of such a database is the Clinical Practice Research Datalink (CPRD).

CPRD (previously the General Practice Research Database) is one of the largest longitudinal databases in the world containing anonymised EHR data (e.g. demographics, symptoms, behavioural factors, tests, etc.) for 11.3 million patients in the UK [15]. CPRD has been used in over 1500 observational research studies covering a variety of disease and therapeutic areas [16]. However, it is currently not known to what extent CPRD studies have been used to inform clinical practice.

In this context, this study aimed at systematically reviewing the literature to identify guidelines or guidances published from 2000 onwards in England which have referenced studies using RWD from the CPRD. The review has focused particularly on governmental organisations (in terms of data providers and guideline developers) as the UK healthcare system is one of the best integrated systems globally.

\section{Methods}

\section{Operational definitions}

Guidances and guidelines were categorised according to the definitions provided by the NICE.

The categories were as follows:

- NICE Clinical Knowledge Summaries: "A readily accessible summary of the current evidence base and practical guidance on best practice in respect of over 330 common and/or significant primary care presentations" [17].

- Technology appraisals guidance: "Recommendations on the use of new and existing medicines and treatments within the NHS" [18].

- Clinical guidelines: "Recommend how healthcare professionals should care for people with specific conditions" [19].

Results which did not fit these categories but focused on the delivery of medications were defined as 'prescribing' guidelines.

\section{Search strategy}

This systematic review adopted the Preferred Reporting Items for Systematic Reviews and Meta-Analyses (PRISMA) guidelines [20] and was in line with the protocol agreed by all authors.

Guidelines and guidances of interest were identified by a systematic search of four databases from 1st January 2000 to 21st March 2016 (last day of search update): NICE Evidence Search, Medline PubMed, Embase and 
the National Clinical Guideline Centre. All four databases were searched for guideline/guidance documents referencing studies using data from CPRD using combinations of the following keywords: "CPRD", "Clinical Practice Research Datalink", "GPRD”, and "General Practice Research Database". Indicatively for Medline the following algorithm was used: ((CPRD OR "Clinical Practice Research Datalink" OR GPRD OR "General Practice Research Database")) AND "guideline"[Publication Type]) AND ("2000/01/01"[Date - Publication]: “3000"[Date - Publication]).

A search diary recording the search results for each database and the meeting of the inclusion/ exclusion criteria for each document was maintained. The specific inclusion criteria were as follows: 1) a UK guideline/ guidance and 2) references research using data from CPRD or GPRD. Documents were excluded if they met one or more of the following criteria: 1) Irrelevant, 2) Not written in English, 3) Not a guidance or guideline (any other primary or secondary research paper), 4) Only mentions CPRD/GPRD (e.g. as a potential source for future studies), 5) Not available (as being updated) and 6) Draft documents or in consultation. Reference lists of all studies previously identified as having met the inclusion criteria were also manually reviewed for additional relevant documents.

The search and assessment of eligibility for included studies were performed by two reviewers working independently. Any duplicate documents were consolidated. All decisions were reached by consensus, with the addition of a third reviewer where required. A relevant PRISMA flow chart was constructed to detail the number of papers retrieved and the steps undertaken.

\section{Data extraction}

All data were extracted by two independent investigators and consensus was reached after the involvement of a third investigator where required. Full text was available for all documents. The following information was extracted for each identified document meeting the inclusion criteria: title, year of publication, disease area, the CPRD studies cited, the exact sentences referencing and the type of guideline/ guidance and the references. Each guidance document was categorised by disease area following the categories of the British National Formulary (BNF). The information was then summarised and tabulated in a standard form. In the assessment of the results, studies referenced in more than one guideline document, were treated separately as providing different evidence in each.

A purely descriptive approach was adopted for data synthesis. Sums and means were derived where appropriate. No further statistical analysis was undertaken. As this review did not include any primary research, no form of quality assessment was necessary.

\section{Results \\ Search results}

The PRISMA search strategy yielded 297 documents in total from four bibliographic databases, of which 293 were not duplicates. Following screening, 178 documents were excluded as they were not a guidance or guideline. A further 90 records were excluded based on the other exclusion criteria. In total, 25 documents were included in the final review (Fig. 1), referencing a total of 43 CPRD/GPRD studies.

\section{Study characteristics}

Baseline characteristics and detailed information of the included studies, including how the evidence from these studies was used to inform the documents, are listed in Table 1 . Of the 25 documents included in the review, 12 were guidelines while the remainder $(N=13)$ were guidances. The guidelines/guidances were published between 2007 and 2015 with 2008 being the only year a guidance/guideline referencing CPRD had not been published. No relevant documents were identified before 2007. The majority of documents were published in 2012 and 2015 ( $N=7$ for each year). Approximately 16 of the documents were published in the last 3 years. Of the guidelines identified, ten were clinical and the remainder were prescribing. Of the guidances identified, seven were Clinical Knowledge Summaries, two were prescribing, three were Technology Appraisals and the remainder were clinical.

The guidelines and guidances covered 12 topics (grouped according to the BNF). The majority of the documents $(N=7)$ were focused on diseases of the Central Nervous system (CNS). The guidances covered eight topics with the majority again focusing on diseases of the CNS. The Guidelines covered seven topics with the majority focusing on Infections, the Central nervous system and Ear, nose and oropharynx ( $N=4$ for each topic). The top seven disease areas are listed in Table 2.

Forty-three studies using CPRD data were referenced in the 25 documents with three studies receiving the most citations [21, 22, 24]. The guideline which referenced the most CPRD studies $(N=15)$ was 'Suspected Cancer: recognition and referral' (2015). Only three guidances referenced more than one CPRD study $(N=2$ in all cases),'Osteoporosis: assessing the risk of fragility fracture' (2012), 'Rivaroxaban for the prevention of stroke and systemic embolism in people with atrial fibrillation' (2012), and 'Sore throat - acute' (2012).

The evidence used from CPRD studies can be grouped into five categories. Almost three quarters provided information on disease epidemiology $(N=32)$ while the 


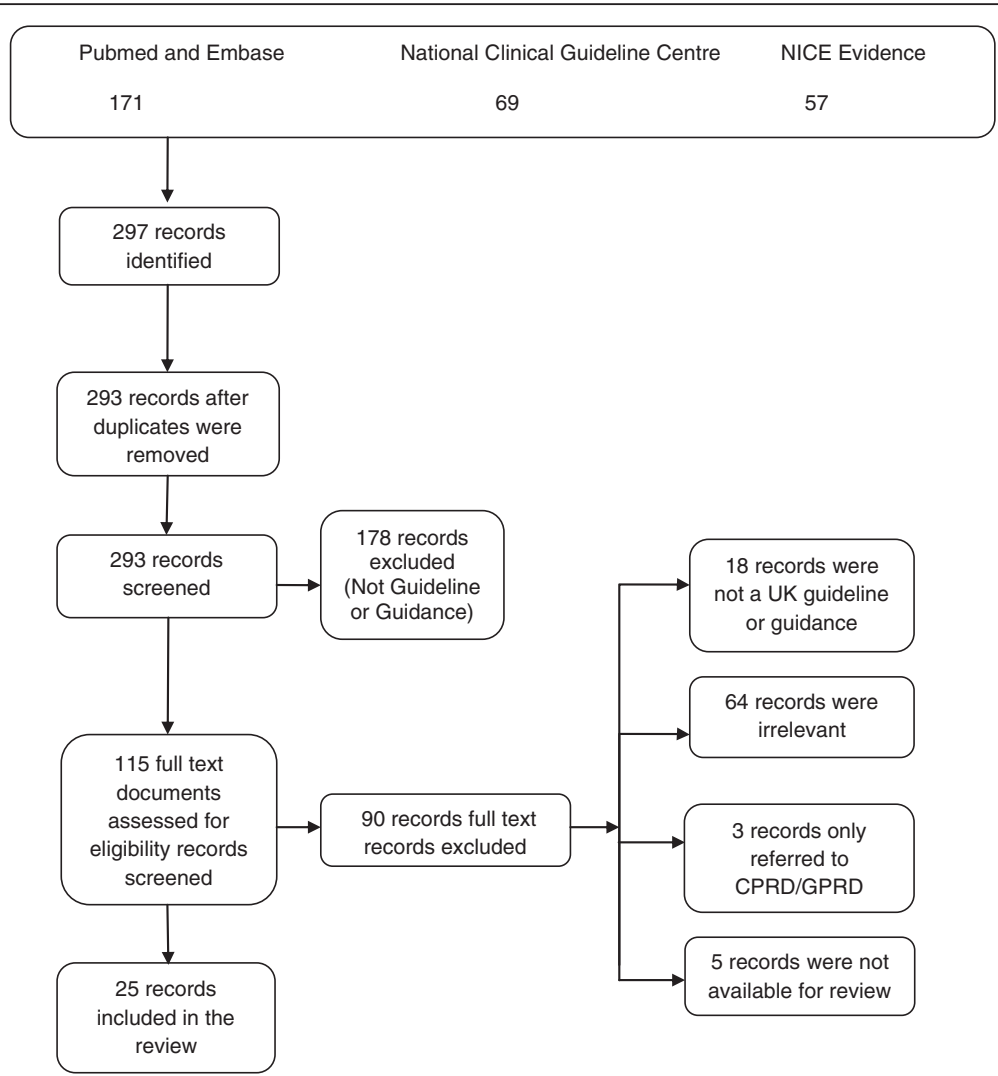

Fig. 1 Flowchart for the systematic review following the PRISMA methodology. 297 documents in total were identified from four bibliographic databases, of which 293 were not duplicates. Following screening, 178 documents were excluded as they were not a guidance or guideline. A further 90 records were excluded based on the other exclusion criteria. 25 documents were included in the final review

remainder were in relation to pharmacovigilance $(N=12)$, pharmacoepidemiological evidence $(N=5)$, incidence or prevalence rates $(N=3)$ and health utilisation $(N=1)$.

\section{Discussion}

\section{Main findings}

The results of this study show RWD from CPRD have not been used to provide input for guidelines and guidances too often. The identified numbers of guidelines and guidances referencing CPRD studies seem significantly small considering that over 900 documents providing guidance have been published by NICE since its inception [64] and that CPRD has been used in over 2000 publications since it began its existence in 1987. These findings correlate to a similar study by Tricoci et al. in the USA who conducted a review of the American College of Cardiology (ACC) and the American Heart Association (AHA) guidelines in 2009. The study identified 16 relevant guidelines for their review with only $11 \%$ of the recommendations being based on evidence from multiple sources instead of expert opinion or evidence from a single study [65]. However, the results of this review do show an increase in the frequency of RWD studies being used in guidelines/guidances in recent years. Despite the fact that clinical datasets and large longitudinal databases have been in existence for well over three decades, interest in RWD and large clinical databases for health research to influence guidelines and guidances is still in its infancy. Improvements in data processing, innovation in bioinformatics, the increased uptake of EHR systems, the increased demand for better and more efficient health care and the need for rapid generation of evidence are all contributing towards an increasing trend in its use by researchers, clinicians and policy makers [66].

\section{Disease areas}

Identified documents covered a variety of disease areas demonstrating the breadth of research using RWD generated from EHRs. This is partly due to the range of data available through large healthcare databases and datasets and the depth of the data being enhanced by linking to other datasets.

The majority of the documents focused on diseases or treatments to do with the CNS. It appears, in this area of health, the benefits of RWE are being more utilised. For example, two of the documents refer to the treatment of patients with mental illness which correlates with research trends as several studies have investigated the patterns, drug effects and outcomes of patients used 
Table 1 An overview of the studies included in the review

\begin{tabular}{|c|c|c|c|c|c|}
\hline $\begin{array}{l}\text { Guideline or Guidance } \\
\text { and year of publication }\end{array}$ & Title & Type & Broad Disease Area & $\begin{array}{l}\text { CPRD studies } \\
\text { cited }\end{array}$ & Use of evidence from CPRD data \\
\hline \multirow[t]{3}{*}{ Guideline 2007} & \multirow[t]{3}{*}{$\begin{array}{l}\text { Guidelines for osteoporosis in inflammatory } \\
\text { bowel disease and coeliac disease }\end{array}$} & \multirow[t]{3}{*}{ Clinical } & \multirow[t]{3}{*}{$\begin{array}{l}\text { Gastro-intestinal } \\
\text { system }\end{array}$} & \multirow[t]{3}{*}{3} & $\begin{array}{l}\text { Increased risk of osteoporotic fracture in } \\
\text { patients with Inflammatory Bowel Disease } \\
\text { (Crohn's disease and ulcerative colitis) who } \\
\text { use steroids; severity of disease } \\
\text { (after adjusting for corticosteroid use) also } \\
\text { predicted fracture [21]. }\end{array}$ \\
\hline & & & & & $\begin{array}{l}\text { Increased fracture rates in Inflammatory } \\
\text { Bowel Disease (Crohn's disease and } \\
\text { ulcerative colitis) patients with } \\
\text { age; increased risk of osteoporotic fracture } \\
\text { with steroid use [22]. }\end{array}$ \\
\hline & & & & & $\begin{array}{l}\text { Small increase in fracture risk in patients } \\
\text { with coeliac disease [23]. }\end{array}$ \\
\hline Guideline 2009 & $\begin{array}{l}\text { British Society for Rheumatology and British Health } \\
\text { Professionals in Rheumatology guideline for the } \\
\text { management of gout }\end{array}$ & Clinical & $\begin{array}{l}\text { Musculoskeletal and } \\
\text { joint diseases }\end{array}$ & 1 & Prevalence of gout [24]. \\
\hline Guideline 2009 & $\begin{array}{l}\text { Evidence-based guidelines for treating bipolar disorder: } \\
\text { revised second edition - recommendations from the British } \\
\text { Association for Psychopharmacology }\end{array}$ & Clinical & Central nervous system & 1 & $\begin{array}{l}\text { Slightly greater risk of mortality from CHD } \\
\text { and stroke in patients prescribed a higher } \\
\text { dose of antipsychotics [25]. }\end{array}$ \\
\hline Guideline 2009 & $\begin{array}{l}\text { Guidelines (2008) for the prophylaxis and treatment of } \\
\text { methicillin-resistant Staphylococcus aureus (MRSA) } \\
\text { infections in the United Kingdom }\end{array}$ & Clinical & Infections & 1 & $\begin{array}{l}\text { Incidence of community-acquired MRSA } \\
\text { infections in the UK; association between } \\
\text { the use of quinolone or macrolide in the } \\
\text { year previous to community-acquired } \\
\text { MRSA [26]. }\end{array}$ \\
\hline Guideline 2009 & $\begin{array}{l}\text { BAP updated guidelines: evidence-based guidelines for the } \\
\text { pharmacological management of substance abuse, harmful use, } \\
\text { addiction and comorbidity: recommendations from BAP }\end{array}$ & Clinical & $\begin{array}{l}\text { Central nervous } \\
\text { system }\end{array}$ & 1 & $\begin{array}{l}\text { No substantive relationship between } \\
\text { varenicline and possible adverse events } \\
\text { (including depressed mood, agitation and } \\
\text { suicidal thoughts) [27]. }\end{array}$ \\
\hline Guidance 2009 & Progestogen-only Pills & Prescribing & $\begin{array}{l}\text { Obstetrics, gynaecology and } \\
\text { urinary-tract disorders }\end{array}$ & 1 & $\begin{array}{l}\text { No effect on risk of Venous } \\
\text { thromboembolism (VTE) with } \\
\text { progestogens used for contraception, } \\
\text { and not in higher doses, for the treatment } \\
\text { of gynaecological disorders [28]. }\end{array}$ \\
\hline Guideline 2009 & $\begin{array}{l}\text { British Association of Dermatologists' guidelines for biologic } \\
\text { interventions for psoriasis } 2009\end{array}$ & Prescribing & Skin & 1 & $\begin{array}{l}\text { Increased risk of herpes zoster with biologic } \\
\text { therapy (infliximab, etanercept and anakinra) } \\
\text { compared with DMARDs in patients with } \\
\text { rheumatoid arthritis (RA) [29]. }\end{array}$ \\
\hline Guideline 2010 & $\begin{array}{l}\text { Chronic heart failure: Management of chronic heart failure in } \\
\text { adults in primary and secondary care }\end{array}$ & Clinical & $\begin{array}{l}\text { Cardiovascular } \\
\text { system }\end{array}$ & 1 & $\begin{array}{l}\text { Post-trial mortality estimates in heart failure } \\
\text { patients [30]. }\end{array}$ \\
\hline Guideline 2011 & $\begin{array}{l}\text { Evidence-based guidelines for the pharmacological treatment } \\
\text { of schizophrenia: recommendations from the British Association } \\
\text { for Psychopharmacology }\end{array}$ & Clinical & $\begin{array}{l}\text { Central nervous } \\
\text { system }\end{array}$ & 1 & $\begin{array}{l}\text { Metabolic derangements are risk factors } \\
\text { for stroke and myocardial infarction [25]. }\end{array}$ \\
\hline
\end{tabular}


Table 1 An overview of the studies included in the review (Continued)

Clinical Knowledge Central nervous

Summary

system

Guideline 2012

Psoriasis

Clinical

Skin

Clinical Knowledge Ear, nose and oropharynx Summary

Technology

Cardiovascular system

Rivaroxaban for the prevention of stroke and systemic embolism in people with atrial fibrillation

Medications in recovery: re-orientating drug dependence treatment

Osteoporosis: assessing the risk of fragility fracture

Guidance 2012

Guideline 2012

Infection: Prevention and control of healthcare-associated infections in primary and community care

Guideline 2013

Omalizumab for treating severe persistent allergic asthma (review of technology appraisal guidance 133 and 201)

Guidance 2014 appraisals

Prescribing

Central nervous system

Clinical

Endocrine system

Clinical

Infections

Technology

Respiratory system

appraisals

Clinical Knowledge Obstetrics, gynaecology and 1 Summary
No clear association between varenicline self-harm. [27]

Higher risk of mortality from cardiovascular disease or cerebrovascular disease in severe psoriasis patients compared to an unexposed cohort. [31]

Higher risk of mortality from diabetes in psoriasis patients compared to an unexposed cohort; the risk of mortality from liver disease was not significantly higher [32].

Incidence of major adverse cardiac events was higher in psoriasis patients [33].

Low benefit of using antibiotics to prevent complications from acute sore throat [34].

Incidence of quinsy was low but develops very quickly: low doses of antibiotics less likely to protect against quinsy [35].

Prevalence of atrial fibrillation (AF) in people aged 55-64 in the UK [36].

Event rates according to baseline leve of stroke risk and the distribution of patients with different CHADS2 scores [37]

Increased risk of mortality in the first few weeks of prescribing opioid substitution Therapy (OST); overall mortality ratio was lower in those prescribed OST than in opioid users [38].

Included in systematic review for the 'history of falls' as a prognostic factor for the risk of fragility of falls in Osteoporosis [39].

Dose effect relationship between steroid use and fracture risk [40].

Probability of treatment failure in young women with urinary tract infections [41].

Mortality rate for severe persistent allergic asthma patients being treated with

Omalizumab [42].

Higher risk of venous thromboembolism VTE) associated with Yasmin ${ }^{\circledast}$ than the 
Table 1 An overview of the studies included in the review (Continued)

$\begin{array}{ll}\text { Guidance } 2015 & \text { Gout } \\ \text { Guidance } 2015 & \text { Immunisations - seasonal influenza }\end{array}$

Guidance 2015

Otitis externa

Guidance 2015

Vortioxetine for treating major depressive episode

Guidance 2015

Multiple sclerosis

Guideline 2015

Guideline 2015

Suspected Cancer: recognition and referral HIV-positive adults 2015
Clinical Knowledge Musculoskeletal and joint 1 Summary diseases

Clinical Knowledge Immunological products Summary

$$
\text { and vaccines }
$$

Clinical Knowledge Ear, nose and oropharynx Summary

Technology

appraisals

Central nervous system

\section{Clinical Knowledg} Summary

Prescribing

Infections

British HIV Association guidelines on the use of vaccines in

Clinical

Malignant disease and immunosuppression risk of VTE with COCs containing

levonorgestrel [43].

Prevalence of Gout [24].

No association between influenza vaccines and Guillain-Barré syndrome [44].

Prescribing patterns of oral antibiotics for otitis externa [45].

Provided drug utilisation and healthcare resource data and comparative outcomes for diagnosed patients prescribed the specific product [46].

Prevalence of Multiple sclerosis [47]

Vaccinations protect against severe disease, complications such as bronchopneumonia, hospital admission, and mortality in the elderly and those with underlying conditions [48].

Provided the positive predictive values of symptoms for lung, oesophageal, stomach, colorectal, bladder and renal cancer to

improve the diagnosis of such cancers [49].

Provided the positive predictive values of $s$ ymptoms for pancreatic cancer to improve the diagnosis of this cancer [50].

Provided the positive predictive values of symptoms for oesophageal and stomach cancer to improve the diagnosis of these cancer [51].

Provided the positive predictive values of symptoms for breast cancer to improve the diagnosis of this cancer [52].

Provided the positive predictive values of symptoms for endometrial cancer to improve the diagnosis of this cancer [53]

Provided the positive predictive values of symptoms for bladder cancer to improve the diagnosis of this cancer [54].

Provided the positive predictive values of symptoms for renal cancer to improve the diagnosis of this cancer [55]. 
Table 1 An overview of the studies included in the review (Continued)

Provided the positive predictive values of symptoms for myeloma to improve the diagnosis of this cancer [56]

Provided the positive predictive values of symptoms for bladder cancer to improve the diagnosis of this cancer [57].

Provided the positive predictive values of symptoms for urological cancer, brain cancer, CNS cancer, neuroblastoma, etinoblastoma and Wilms' tumour in children to improve the diagnosis of these cancers [58].

Provided the positive predictive values of symptoms for urological cancer, brain cancer, CNS cancer,

leukaemia/lymphoma, Non-Hodgkin's lymphoma, Hodgkin's lymphoma, bone sarcoma, soft tissue sarcoma, abdominal cancer, neuroblastoma, retinoblastoma and Wilms' tumour in children and young adults to improve the diagnosis of these cancers [59].

Provided the positive predictive values of symptoms for brain cancer, CNS cancer, leukaemia, Non-Hodgkin's lymphoma,

Hodgkin's lymphoma, bone sarcoma, soft tissue sarcoma neuroblastoma, $r$ etinoblastoma and Wilms' tumour in children, young adults and adults to improve the diagnosis of these cancers [60].

Provided the positive predictive values of symptoms

for brain and CNS cancer to improve the diagnosis of these cancer [61].

Provided the positive predictive values of symptoms for brain and CNS cancer in children and young adults to improve diagnosis of these cancers [62]

Provided the positive predictive values of symptoms for brain, lung and CNS cancer to improve diagnosis of these cancers [63]. 
Table $\mathbf{2}$ Top seven disease areas identified in the review

\begin{tabular}{ll}
\hline Disease area & Number of guidelines and guidances \\
\hline Central nervous system & 7 \\
Infections & 3 \\
$\begin{array}{l}\text { Obstetrics, gynaecology and } \\
\text { urinary-tract disorders }\end{array}$ & 2 \\
$\begin{array}{l}\text { Musculoskeletal and joint } \\
\text { diseases }\end{array}$ & 2 \\
Ear, nose and oropharynx & 2 \\
Skin & 2 \\
Cardiovascular system & 2 \\
\hline
\end{tabular}

RWD [67]. The document which cited the most CPRD studies was the guideline on Suspected Cancer which highlighted the need for better methods of diagnosis and early detection and gave precise and more up-to-date information on how to detect over 200 cancers [16]. This reflects the increased interest in this disease area where several studies have looked into using EHRs to 'flag' recognised diagnostic clues in a timely manner [68]. This will have a substantial benefit to cancer patients as delays in diagnosis have been linked to poorer prognosis [69].

Evidence from studies using CPRD is significantly under-represented in conditions which are primarily treated in primary care (e.g. Diabetes, Obesity, Asthma, etc.). This is not because there is a lack of studies on the subject. The possible reasons for this have already been discussed above and as a result, there needs to be a review of the kind of evidence used in guidelines and guidances, for if the data is not for the purpose it was created then it is a waste of a potentially health-changing resource.

Studies using CPRD data were not referenced in guidelines in other disease areas at all, such as nutrition and blood, eye, and anaesthesia. For most of these disease areas, the reason is quite clear. CPRD currently has no or limited data on diseases and treatments that are mainly administered in secondary care (e.g. drugs administered through the eye) and there are no efficient centralised databases containing such information. However, the linking of datasets from varied health settings can provide a fuller picture of disease and health outcomes in the general population and therefore provide even more robust evidence [70]. A good example of this is the cardiovascular disease research using linked bespoke studies and electronic health records (CALIBER) dataset comprising of CPRD GOLD data and linked data from Hospital Episodes Statistics (HES), deprivation data, the Office for National Statistics (ONS) mortality information and the Myocardial Ischaemia National Audit Project (MINAP) [71]. This was a bespoke linked dataset to perform studies to improve the health of patients suffering from cardiovascular diseases and has been used in a number of useful studies, for example, to identify new associations for a range of risk factors in cardiovascular disease [72].

This shows that the ability to link datasets from a variety of sources provides immense opportunity to not only get a fuller picture of a patient's medical history, but also investigate the interactions and associations between different treatments/diseases in different clinical settings and possibly developing predictors of health outcomes [73].

\section{The future}

Looking towards how clinical evidence can be improved, one would directly look into the organisations providing the data. As CPRD and other data providers continue to expand their linkages to other data sources and the benefits of linked data sources increase in recognition, funds should be invested in creating datasets in all sectors of health. This will enable healthcare professionals to make sound decisions based on RWD, regardless of their line of work. The Health and Social Care Information Centre (HSCIC) who manage and maintain the balance between the sharing of information for community benefit and respecting the confidentiality and wishes of patients have been key in enabling research through linked data in the UK [74].

\section{Strengths and limitations}

There are several strengths to this study. Firstly, it was conducted using the gold-standard method for conducting systematic reviews [75]. The PRISMA methodology has been found to improve the completeness of systematic review and meta-analysis reporting [76]. Furthermore, an exhaustive search of multiple bibliographic databases was followed. NICE and the National Clinical Guideline Centre are the main databases for UK clinical guidelines and guidances with the majority of healthrelated organisations referencing these sites for further information or access. The study focused on identifying research which has used data from the most widely used source of RWE (CPRD) and in a country that uses medical informatics research extensively. Lastly, the authors have the relevant experience and knowledge of CPRD, the provision of healthcare in the UK and the process for conducting systematic reviews.

However, limitations of the review need to be acknowledged. Firstly, this review focused only on guidelines and guidances which used evidence from studies using CPRD data. There are other longitudinal databases in the UK such as The Health Improvement Network (THIN) and QResearch. It also did not look into what type of data was used in each study (e.g. use of linked data). For future studies, it would be interesting to investigate whether evidence from other longitudinal databases have been used to inform guidelines/guidances. This study also focused 
on guidelines and guidances published for health and social care in England. Future studies could compare how RWD is used not only nationally but also internationally and identify the trends and differences that may exist. Lastly, guidelines and guidances which were currently 'under review' were not included in the review as they were liable to change once published. Therefore it would be worth conducting the review again at such a time when these guidelines/guidances become available to see how they affect the current results.

\section{Conclusions}

In this systematic review, we confirmed that Real World Evidence from the Clinical Practice Research Datalink has been used inconsistently but increasingly in the last decade, to inform guidelines and guidances published in the United Kingdom. The increased uptake in recent years, noted in our results, shows that this area of healthcare is changing and this review captures a phase in this transition. To capitalise on the potential value of using Real World Evidence, researchers need to ensure they undertake research of translational value to the healthcare community. Organisations which develop guidelines should also work to identify Real World Evidence sources which will give a more realistic view of how an intervention works in actual healthcare settings. Finally, key points extrapolated from our review include increasing the quality of available Real World Evidence (which will require investment on capacity, skills and accessibility) and maintaining public trust (which will be key for wider uptake).

\begin{abstract}
Abbreviations
ACC, American college of cardiology; AHA, American heart association; BNF, British national formulary; CALIBER, cardiovascular disease research using linked bespoke studies and electronic health records; CNS, central nervous system; CPRD, Clinical Practice Research Datalink; EHR, electronic health record; HES, Hospital Episodes Statistics; HSCIC, Health and Social Care Information Centre; MINAP, myocardial ischaemia national audit project; NHS, National Health Service; NICE, National Institute for health and Care Excellence; ONS, Office for National Statistics; PRISMA, preferred reporting items for systematic reviews and meta-analyses; $R C T$, randomised controlled trial; RWD, real world data; $R W E$, real world evidence; THIN, the health improvement network
\end{abstract}

\section{Acknowledgments}

The contributions of Dr Tim Williams and Tarita Murray-Thomas are acknowledged in advising and reviewing for this study.

\section{Funding}

This research received no specific grant from any funding agency in the public, commercial, or not-for-profit sectors.

\section{Availability of data and materials}

The results of the study are included in the manuscript. The search algorithms used for the four databases was as follows:

NICE Evidence Search: "CPRD" or "Clinical Practice Research Datalink" OR

"GPRD" OR "General Practice Research Database".

Medline PubMed: ("CPRD" OR "Clinical Practice Research Datalink" OR

"GPRD" OR "General Practice Research Database") AND guid*.

Embase: ("CPRD" OR "Clinical Practice Research Datalink" OR "GPRD" OR

"General Practice Research Database") AND guid*.

The National Clinical Guideline Centre: "CPRD" or "Clinical Practice Research Datalink" OR "GPRD" OR "General Practice Research Database".

\section{Authors' contributions}

$\mathrm{JO}$ contributed to the design of the study, performed the search and selected the eligible documents. JO also extracted the data and drafted the manuscript. JCa contributed to the design of the study, agreement on study inclusion and drafted parts of and edited the manuscript. AK contributed to the design of the study, performed the search and selected the eligible documents, drafted parts of and edited the manuscript. All authors have read and approved the final manuscript.

\section{Competing interests}

The authors were employees of the Medicines and Healthcare products Regulatory Agency at the time when this research was carried out. They declare no other competing interests.

\section{Consent for publication}

Not applicable.

\section{Ethics approval and consent to participate}

This study is a systematic review of published guidelines and guidances. It was therefore not necessary to apply for ethical approval.

Received: 13 February 2016 Accepted: 20 July 2016

Published online: 26 July 2016

\section{References}

1. Clancy CM, Cronin K. Evidence-based decision making: global evidence, local decisions. Health Aff (Millwood). 2005;24:151-62.

2. Sniderman $A D$, Furberg $C D$. Why guideline-making requires reform. JAMA. 2009:301:429-31.

3. Shaneyfelt TM, Centor RM. Reassessment of clinical practice guidelines: go gently into that good night. JAMA. 2009;301:868-9.

4. Wilson M. Big data in health care decisions: where Are We Now and what does the future hold? Values Outcomes Spotlight. 2015;1:7-9.

5. Isern D, Moreno A. Computer-based execution of clinical guidelines: a review. Int J Med Inform. 2008;77:787-808.

6. Rawlins MD. NICE: moving onward. N Engl J Med. 2013:369:3-5.

7. Zhang Z. Big data and clinical research: perspective from a clinician. J Thorac Dis. 2014;6:1659-64.

8. Rawlins M. De Testimonio: on the evidence for decisions about the use of therapeutic interventions. Clin Med. 2008;8:579-88.

9. Schneeweiss S, Avorn J. A review of uses of health care utilization databases for epidemiologic research on therapeutics. J Clin Epidemiol. 2005;58:323-37.

10. Garrison LP, Neumann PJ, Erickson P, et al. Using real-world data for coverage and payment decisions: the ISPOR Real-World Data Task Force report. Value Health. 2007;10:326-35.

11. Wang W, Krishnan E. Big data and clinicians: a review on the state of the science. JMIR Med Inform. 2014;2:1-11.

12. Murdoch TB, Detsky AS. The inevitable application of big data to health care. JAMA. 2013;309:1351-2.

13. Roden DM, Pulley JM, Basford MA, et al. Development of a large-scale de-identified DNA biobank to enable personalized medicine. Clin Pharmacol Ther. 2008;84:362-9.

14. Cáceres SB. Electronic health records: beyond the digitization of medical files. Clinics (Sao Paulo). 2013;68:1077-8.

15. Herrett E, Gallagher AM, Bhaskaran K, et al. Data resource profile: clinical practice research datalink (CPRD). Int J Epidemiol. 2015;44:827-36.

16. Kousoulis AA, Rafi I, de Lusignan S. The CPRD and the RCGP: building on research success by enhancing benefits for patients and practices. Br I Gen Pract. 2015;65:54-5.

17. NICE. Clinical knowledge summaries. NICE. 2016. http://cks.nice.org.uk/\#?char=A. Accessed 21 Mar 2016.

18. NICE. NICE Technology appraisal guidance. NICE. 2016. https://www.nice. org.uk/about/what-we-do/our-programmes/nice-guidance/nice-technologyappraisal-guidance. Accessed 21 Mar 2016

19. NICE. Types of guideline. NICE. 2016. www.nice.org.uk/about/what-we-do/ our-programmes/nice-guidance/nice-guidelines/types-of-guideline. Accessed 21 Mar 2016

20. Liberati A, Altman DG, Tetzlaff J, et al. The PRISMA statement for reporting systematic reviews and meta-analyses of studies that evaluate health care interventions: explanation and elaboration. PLoS Med. 2009;6:e1000100. 
21. Van Staa T-P, Cooper C, Brusse LS, et al. Inflammatory bowel disease and the risk of fracture. Gastroenterology. 2003;125:1591-7.

22. Card T, West J, Hubbard R, et al. Hip fractures in patients with inflammatory bowel disease and their relationship to corticosteroid use: a population based cohort study. Gut. 2004;53:251-5.

23. West J, Logan RFA, Card TR, et al. Fracture risk in people with celiac disease: a population-based cohort study. Gastroenterology. 2003;125:429-36.

24. Mikuls TR, Farrar JT, Bilker WB, et al. Gout epidemiology: results from the UK general practice research database, 1990-1999. Ann Rheum Dis. 2005;64:267-72.

25. Osborn DPJ, Levy G, Nazareth I, et al. Relative risk of cardiovascular and cancer mortality in people with severe mental illness from the united Kingdom's general practice research database. Arch Gen Psychiatry. 2007;64:242-9.

26. Schneider-Lindner V, Delaney JA, Dial S, et al. Antimicrobial drugs and community-acquired methicillin-resistant staphylococcus aureus, United Kingdom. Emerg Infect Dis. 2007;13:994-1000.

27. Gunnell D, Irvine D, Wise L, et al. Varenicline and suicidal behaviour: a cohort study based on data from the general practice research database. BMJ. 2009;339:b3805

28. Vasilakis C, Jick H, del Mar Melero-Montes M. Risk of idiopathic venous thromboembolism in users of progestagens alone. Lancet. 1999;354:1610-1.

29. Smitten AL, Choi HK, Hochberg MC, et al. The risk of herpes zoster in patients with rheumatoid arthritis in the United States and the United Kingdom. Arthritis Rheumatol. 2007;57:1431-8.

30. De Giuli F, Khaw K-T, Cowie MR, et al. Incidence and outcome of persons with a clinical diagnosis of heart failure in a general practice population of 696,884 in the United Kingdom. Eur J Heart Fail. 2005;7:295-302.

31. Mehta NN, Azfar RS, Shin DB, et al. Patients with severe psoriasis are at increased risk of cardiovascular mortality: cohort study using the general practice research database. Eur Heart J. 2010;31:1000-6.

32. Abuabara K, Azfar RS, Shin DB, et al. Cause-specific mortality in patients with severe psoriasis: a population-based cohort study in the U.K. Br J Dermatol. 2010;163:586-92.

33. Mehta NN, Yu Y, Pinnelas $R$, et al. Attributable risk estimate of severe psoriasis on major cardiovascular events. Am J Med. 2011;124:775.e1-6.

34. Petersen I, Johnson AM, Islam A, et al. Protective effect of antibiotics against serious complications of common respiratory tract infections: retrospective cohort study with the UK general practice research database. BMJ. 2007;335:982.

35. Dunn $N$, Lane D, Everitt $H$, et al. Use of antibiotics for sore throat and incidence of quinsy. Br J Gen Pract. 2007;57:45-9

36. Majeed A, Moser K, Carroll K. Trends in the prevalence and management of atrial fibrillation in general practice in England and Wales, 1994-1998: analysis of data from the general practice research database. Heart. 2001;86:284-8.

37. Gallagher AM, Rietbrock S, Plumb J, et al. Initiation and persistence of warfarin or aspirin in patients with chronic atrial fibrillation in general practice: do the appropriate patients receive stroke prophylaxis? J Thromb Haemost. 2008;6:1500-6.

38. Cornish R, Macleod J, Strang J, et al. Risk of death during and after opiate substitution treatment in primary care: prospective observational study in UK general practice research database. BMJ. 2010;341:c5475.

39. Van Staa T-P, Geusens P, Pols HAP, et al. A simple score for estimating the longterm risk of fracture in patients using oral glucocorticoids. QJM. 2005;98:191-8.

40. Van Staa TP, Leufkens HG, Abenhaim L, et al. Oral corticosteroids and fracture risk: relationship to daily and cumulative doses. Rheumatology (Oxford). 2000;39:1383-9.

41. Lawrenson RA, Logie JW. Antibiotic failure in the treatment of urinary tract infections in young women. J Antimicrob Chemother. 2001;48:895-901.

42. De Vries F, Setakis E, Zhang B, et al. Long-acting \{beta\}2-agonists in adult asthma and the pattern of risk of death and severe asthma outcomes: a study using the GPRD. Eur Respir J. 2010;36:494-502.

43. Parkin L, Sharples K, Hernandez RK, et al. Risk of venous thromboembolism in users of oral contraceptives containing drospirenone or levonorgestrel: nested case-control study based on UK general practice research database. BMJ. 2011;342:d2139.

44. Stowe J, Andrews N, Wise L, et al. Investigation of the temporal association of Guillain-barre syndrome with influenza vaccine and influenzalike illness using the United Kingdom general practice research database. Am J Epidemiol. 2009;169:382-8.

45. Rowlands S, Devalia H, Smith C, et al. Otitis externa in UK general practice: a survey using the UK general practice research database. Br J Gen Pract. 2001:51:533-8
46. Byford S, Barrett B, Despiégel N, et al. Impact of treatment success on health service use and cost in depression: longitudinal database analysis. Pharmacoeconomics. 2011;29:157-70.

47. Mackenzie IS, Morant SV, Bloomfield GA, et al. Incidence and prevalence of multiple sclerosis in the UK 1990-2010: a descriptive study in the general practice research database. J Neurol Neurosurg Psychiatry. 2014;85:76-84.

48. Mangtani $P$, Cumberland $P$, Hodgson $C R$, et al. A cohort study of the effectiveness of influenza vaccine in older people, performed using the United Kingdom general practice research database. J Infect Dis. 2004;190:1-10.

49. Jones R, Latinovic R, Charlton J, et al. Alarm symptoms in early diagnosis of cancer in primary care: cohort study using general practice research database. BMJ. 2007;334:1040.

50. Stapley S, Peters TJ, Neal RD, et al. The risk of pancreatic cancer in symptomatic patients in primary care: a large case-control study using electronic records. Br J Cancer. 2012;106:1940-4.

51. Stapley S, Peters TJ, Neal RD, et al. The risk of oesophago-gastric cancer in symptomatic patients in primary care: a large case-control study using electronic records. Br J Cancer. 2013;108:25-31

52. Walker S, Hyde C, Hamilton W. Risk of breast cancer in symptomatic women in primary care: a case-control study using electronic records. $\mathrm{Br} J \mathrm{Gen}$ Pract. 2014;64:e788-93.

53. Walker S, Hyde C, Hamilton W. Risk of uterine cancer in symptomatic women in primary care: case-control study using electronic records. $\mathrm{Br}$ J Gen Pract. 2013;63:e643-8.

54. Shephard EA, Stapley S, Neal RD, et al. Clinical features of bladder cancer in primary care. Br J Gen Pract. 2012;62:e598-604.

55. Shephard E, Neal R, Rose P, et al. Clinical features of kidney cancer in primary care: a case-control study using primary care records. Br J Gen Pract. 2013;63:e250-5.

56. Shephard EA, Neal RD, Rose $P$, et al. Quantifying the risk of multiple myeloma from symptoms reported in primary care patients: a large casecontrol study using electronic records. Br J Gen Pract. 2015;65:e106-13.

57. Price SJ, Shephard EA, Stapley SA, et al. Non-visible versus visible haematuria and bladder cancer risk: a study of electronic records in primary care. Br J Gen Pract. 2014;64:e584-9.

58. Dommett RM, Redaniel MT, Stevens MCG, et al. Features of childhood cancer in primary care: a population-based nested case-control study. $\mathrm{Br}$ J Cancer. 2012;106:982-7.

59. Dommett RM, Redaniel T, Stevens MCG, et al. Risk of childhood cancer with symptoms in primary care: a population-based case-control study. Br J Gen Pract. 2013;63:e22-9.

60. Dommett RM, Redaniel MT, Stevens MCG, et al. Features of cancer in teenagers and young adults in primary care: a population-based nested case-control study. Br J Cancer. 2013;108:2329-33.

61. Kernick D, Stapley S, Goadsby PJ, et al. What happens to new-onset headache presented to primary care? A case-cohort study using electronic primary care records. Cephalalgia. 2008;28:1188-95.

62. Kernick D, Stapley S, Campbell J, et al. What happens to new-onset headache in children that present to primary care? A case-cohort study using electronic primary care records. Cephalalgia. 2009;29:1311-6.

63. Hamilton W, Kernick D. Clinical features of primary brain tumours: a case-control study using electronic primary care records. Br J Gen Pract. 2007:57:695-9.

64. Rawlins M. NICE times: a valedictory dispatch. Lancet. 2013:381:2225-7.

65. Tricoci P, Allen JM, Kramer JM, et al. Scientific evidence underlying the ACC/ AHA clinical practice guidelines. JAMA. 2009;301:831-41.

66. Raghupathi W, Raghupathi V. Big data analytics in healthcare: promise and potential. Heal Inf Sci Syst. 2014;2:1-10.

67. Howard L, Kirkwood G, Leese M. Risk of hip fracture in patients with a history of schizophrenia. Br J Psychiatry. 2007;190:129-34.

68. Singh $H$, Hirani $K$, Kadiyala $H$, et al. Characteristics and predictors of missed opportunities in lung cancer diagnosis: an electronic health record-based study. J Clin Oncol. 2010;28:3307-15.

69. Murphy DR, Laxmisan A, Reis BA, et al. Electronic health record-based triggers to detect potential delays in cancer diagnosis. BMJ Qual Saf. 2014;23:8-16.

70. Bradley CJ, Penberthy L, Devers KJ, et al. Health services research and data linkages: issues, methods, and directions for the future. Health Serv Res. 2010;45:1468-88.

71. Denaxas SC, George J, Herrett E, et al. Data resource profile: cardiovascular disease research using linked bespoke studies and electronic health records (CALIBER). Int J Epidemiol. 2012;41:1625-38. 
72. Asaria M, Grasic K, Walker S. Using linked electronic health records to estimate healthcare costs: Key challenges and opportunities.

Pharmacoeconomics. 2016;34:155-60.

73. Fleurence RL, Naci H, Jansen JP. The critical role of observational evidence in comparative effectiveness research. Health Aff. 2010;29:1826-33.

74. Health \& Social Care Information Centre. A guide to confidentiality in health and social care. Health \& Social Care Information Centre. 2013. www.hscic. gov.uk/media/12822/Guide-to-confidentiality-in-health-and-social-care/pdf/ HSCIC-guide-to-confidentiality.pdf. Accessed 18 Oct 2015.

75. Moher D, Liberati A, Tetzlaff J, et al. Preferred reporting items for systematic reviews and meta-analyses: the PRISMA statement. BMJ. 2009;339:b2535.

76. Tunis AS, McInnes MDF, Hanna R, et al. Association of study quality with completeness of reporting: have completeness of reporting and quality of systematic reviews and meta-analyses in major radiology journals changed since publication of the PRISMA statement? Radiology. 2013;269:413-26.

\section{Submit your next manuscript to BioMed Central} and we will help you at every step:

- We accept pre-submission inquiries

- Our selector tool helps you to find the most relevant journal

- We provide round the clock customer support

- Convenient online submission

- Thorough peer review

- Inclusion in PubMed and all major indexing services

- Maximum visibility for your research

Submit your manuscript at www.biomedcentral.com/submit 